\title{
The Impact of Delayed Diagnosis of Alpha-1 Antitrypsin Deficiency: The Association Between Diagnostic Delay and Worsened Clinical Status
}

\author{
Vickram Tejwani, Amy S Nowacki, Erica Fye, Christopher Sanders, and James K Stoller
}

\begin{abstract}
BACKGROUND: Alpha-1 antitrypsin deficiency is frequently underrecognized. Individuals with symptoms often experience long diagnostic delays. Although a delayed diagnosis is logically presumed to be associated with adverse effects, confirmatory evidence that a delay in diagnosis confers harm is sparse. The current study characterized the association between a delayed diagnosis and the clinical status at the time of diagnosis. METHODS: Patients with newly diagnosed severe deficiency of alpha-1 antitrypsin received questionnaires that assessed self-reported diagnostic delay, the $\mathrm{St}$ George Respiratory Questionnaire (SGRQ) and COPD Assessment Test. Results of spirometry were retrieved and the relationship between the diagnostic delay interval and $\mathrm{FEV}_{1} \%$ predicted, SGRQ, and COPD Assessment Test were assessed. RESULTS: Forty subjects were recruited (31 with PI*ZZ, 9 with PI*SZ). Values for $\mathrm{FEV}_{\mathbf{1}} \%$ predicted, SGRQ, and COPD Assessment Test were available for 17, 40, and 32 subjects, respectively. The relationship between the diagnostic delay interval and all outcomes was directionally consistent with an adverse impact of increasing diagnostic delay. For each additional year of diagnostic delay, the subject's $\mathrm{FEV}_{\mathbf{1}} \%$ predicted decreased by $0.3 \%(P=.66)$, The SGRQ Total score increased by 1.6 points $(P<.001)$, and the COPD Assessment Test score increased by 0.7 points $(P=.004)$. CONCLUSIONS: The results of this analysis were consistent with a delayed diagnosis of alpha- 1 antitrypsin deficiency being associated with worse COPD-related symptoms and functional status, and with a trend toward worsened air-flow obstruction. Given that alpha-1 antitrypsin deficiency is associated with accelerated emphysema progression, these findings underscore the importance of early detection of alpha- 1 antitrypsin deficiency and reinforce guidelines that endorse alpha-1 antitrypsin deficiency testing in all adults with fixed air-flow obstruction and first-degree relatives of individuals with severe deficiency of alpha-1 antitrypsin. Key words: chronic obstructive pulmonary disease; alpha-1 antitrypsin deficiency; diagnostic delay. [Respir Care 2019;64(8):915-922. (C) 2019 Daedalus Enterprises]
\end{abstract}

\section{Introduction}

Alpha-1 antitrypsin deficiency is frequently underrecognized, with persisting evidence over many years of de-

Dr Tejwani is affiliated with Pulmonary and Critical Care, Johns Hopkins Hospital, Baltimore, Maryland. Dr Nowacki is affiliated with Quantitative Health Sciences, Cleveland Clinic, Cleveland, Ohio. Ms Fye and $\mathrm{Mr}$ Sanders are affiliated with Biocerna, LLC, Fulton, Maryland. Dr Stoller is affiliated with Education Institute, Respiratory Institute, Cleveland Clinic, Cleveland, Ohio.

This study was supported by a grant from CSL-Behring.

Dr Tejwani, Dr Nowacki, Ms Fye, and Mr Sanders report grants from CSL-Behring during the conduct of the study. Dr Stoller serves as a con- layed diagnosis and the need for affected individuals to see multiple physicians before diagnosis. ${ }^{1-7}$ At the same time, alpha- 1 antitrypsin deficiency is a progressive disease, with evidence that individuals with severe deficiency experience accelerated loss of lung function and lung density. ${ }^{8,9}$

\footnotetext{
sultant to various companies regarding alpha- 1 antitrypsin deficiency, including Grifols, Shire, CSL Behring, Arrowhead Pharmaceuticals, 23andMe, InhibRx, and Vertex; has received grant funding from CSL Behring, the National Heart, Lung, and Blood Institute, and the Alpha-1 Foundation; and serves as a member of the board of directors of the Alpha-1 Foundation.

Dr Tejwani gave an oral presentation of the preliminary results at the American College of Chest Physicians conference, held October 29, 2017, Toronto, Canada.
} 


\section{Diagnostic Delay in Alpha-1 Antitrypsin Deficiency}

It therefore is reasonable to suspect that a delay in diagnosing severe alpha- 1 antitrypsin deficiency is associated with worsened clinical status at the time of the initial diagnosis. Put simply, we hypothesized that the longer the delay in diagnosing alpha-1 antitrypsin deficiency, the more advanced the patient's emphysema and the more symptomatic the patient is likely to be.

Indeed, an association between delayed diagnosis and worsened clinical status at the time of initial diagnosis has been established in other diseases, including Crohn disease, ${ }^{10}$ eosinophilic esophagitis, ${ }^{11}$ psoriatic arthritis, ${ }^{12}$ and spondyloarthritis. ${ }^{13}$ In alpha-1 antitrypsin deficiency, in keeping with the notion that delayed diagnosis can confer harm, individuals diagnosed with the disease because of lung symptoms experience a poorer prognosis than those diagnosed as asymptomatic family members of probands. ${ }^{14}$ Yet, surprisingly, despite the evidence that emphysema that accompanies alpha-1 antitrypsin deficiency is progressive, to our knowledge, direct evidence that a delayed diagnosis of alpha- 1 antitrypsin deficiency confers harm is not available.

The current study was undertaken to address the clinical impact of diagnostic delay in alpha- 1 antitrypsin deficiency. We hypothesized that a longer delay between initial symptoms and initial diagnosis in alpha-1 antitrypsin deficiency would be associated with worsened clinical status at the time of initial diagnosis. To examine this hypothesis, we assessed spirometry, St George Respiratory Questionnaire ${ }^{15}$ (SGRQ) ratings, and the COPD Assessment Test ${ }^{16,17}$ (CAT) score in individuals with severe deficiency of alpha-1 antitrypsin at the time of initial diagnosis.

\section{Methods}

The study was approved by the Chesapeake Institutional Review Board MOD00187898. Eligible subjects were newly diagnosed as having severe deficiency of alpha1 antitrypsin based on their managing physician submitting a blood test to the diagnostic laboratory, Biocerna (Fulton, Maryland), between December 2016 and April 2018. Alpha-1 antitrypsin deficiency was defined as having a genotype associated with enhanced emphysema risk (eg, PI*ZZ, PI*Null Null, PI*SZ) and/or a result of serum alpha-1 antitrypsin level below the pro-

Supplementary material related to this paper is available at http:// www.rcjournal.com.

Correspondence: Vickram Tejwani MD, Division of Pulmonary and Critical Care, 1830 E. Monument Street, Fifth floor, Baltimore, MD 21205. E-mail: tejwani@jhmi.edu.

DOI: $10.4187 /$ respcare. 06555

\section{QUICK LOOK}

\section{Current knowledge}

Alpha-1 antitrypsin deficiency is frequently underrecognized, with persisting evidence of a delayed diagnosis and the need to see multiple physicians before a diagnosis. It is reasonable to suspect that a delay in diagnosing severe alpha- 1 antitrypsin deficiency is associated with worsened clinical status at the time of initial diagnosis.

\section{What this paper contributes to our knowledge}

The current study showed that a diagnostic delay was associated with clinical worsening in alpha- 1 antitrypsin deficiency. Specifically, the St George Respiratory Questionnaire score rose by 1.6 points and the COPD Assessment Test score rose by 0.7 per year of diagnostic delay, both of which were statistically significant. The association between a longer diagnostic delay and lower $\mathrm{FEV}_{1} \%$ predicted was directionally consistent with an adverse effect of diagnostic delay, although not statistically significant. For subjects with symptoms but without a family member with alpha1 antitrypsin deficiency that might have prompted earlier testing the median diagnostic delay interval was $5.0 \mathrm{y}$.

tective serum alpha-1 antitrypsin level of $11 \mu \mathrm{M}$ (or $57 \mathrm{mg} / \mathrm{dL}) .{ }^{18}$ Specimens submitted for testing at Biocerna (Gaithersburg, Maryland) were analyzed by using the DNA Advanced Alpha-1 Screening Test developed by Biocerna on behalf of CSL Behring (King of Prussia, Pennsylvania). Quantitative analysis of the serum alpha-1 antitrypsin level was performed by using samples obtained from serum separator cards paired with Roche immunoassays, AAT2 and C-Reactive Protein gen 3 (Roche, Basel, Switzerland) (normal alpha-1 antitrypsin and C-reactive protein (CRP) ranges of $90-200 \mathrm{mg} / \mathrm{dL}$ and $<5 \mathrm{mg} / \mathrm{L}$, respectively). Qualitative assessment of alpha-1 antitrypsin genotype was conducted by using targeted genotyping (TaqMan, Thermo Fisher Scientific, Waltham, Massachusetts) and verified by isoelectric focusing (Sebia USA, Norcross, Georgia).

On confirmation of eligible laboratory results, potential subjects were called by a study coordinator (EF) at Biocerna Labs and invited to participate in this study, which consisted of completing a brief telephonic interview regarding the following: demographic features, family history regarding alpha- 1 antitrypsin deficiency, smoking history, signs and symptoms, the temporal relationship between the onset of alpha-1 antitrypsin deficiency attributable symptoms and initial diagnosis, the number of health- 


\section{Diagnostic Delay in Alpha-1 Antitrypsin Deficiency}
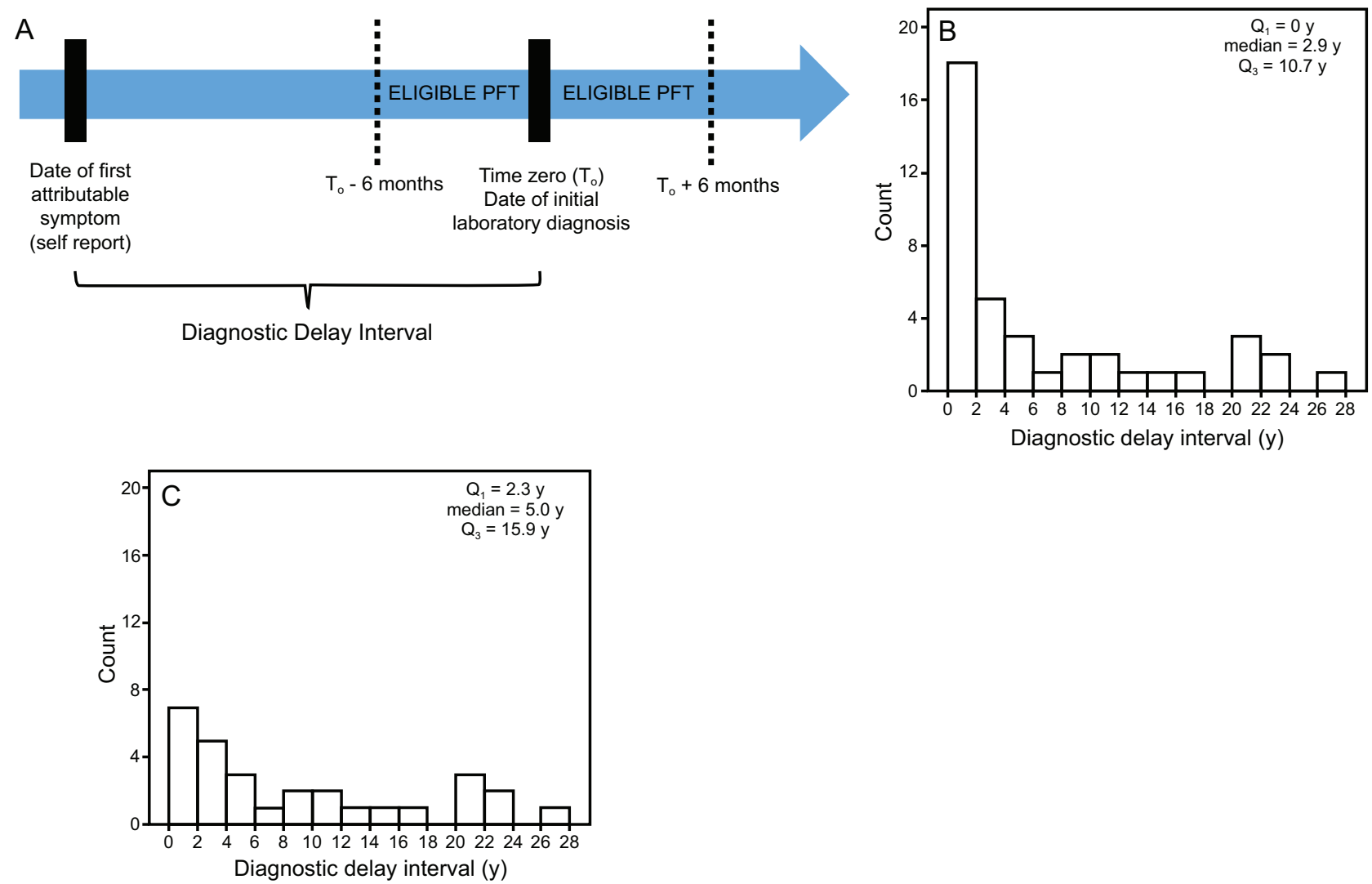

Fig. 1. Timeline of the diagnosis and definition of diagnostic delay interval. A: Timeline. B: Data for all subjects $(N=40)$. C: Data for subjects with symptoms $(n=29)$. Further breakdown of the diagnostic delay interval into patient presentation delay and medical diagnostic delay for the 29 subjects ascertained because of symptoms. This is important because the diagnostic delay interval is the time from the first symptom to diagnosis, but a diagnosis can only be obtained after the patient presents to the clinic. Therefore, one must understand the components of the diagnostic delay for properly interpreting and assessing whether the majority of the delays were due to a delay in patient presentation or in medical diagnosis. The patient presentation delay, however, was much smaller than the medical diagnostic delay (median length 0.5 vs $4.7 \mathrm{y}$, respectively), which indicated that there is room for improvement regarding management of such patients. Of the 29 subjects who experienced a symptom: Patient Presentation Delay Interval(Time from first attributable symptom to Seeking Medical Care) median (Q1-Q3): $6(1,15)$ months, $\min =1$ month; $\max =180$ months. Medical Diagnostic Delay Interval (Time from Seeking Medical Care to Initial Laboratory Diagnosis) median (Q1-Q3): $4.7(1.8,10.5) \mathrm{y}, \min =0.5 \mathrm{y}$; $\max =22.8 \mathrm{y}$.

care providers seen for the alpha-1 antitrypsin deficiency attributable symptom before initial diagnosis, and the SGRQ. ${ }^{15}$ The subjects also completed a brief mail survey (the $\mathrm{CAT}^{16,17}$ ) and were asked to allow study investigators to receive pulmonary function test results.

The date of the initial diagnosis was defined as the date on which the laboratory test that confirmed alpha- 1 antitrypsin deficiency was performed at Biocerna (called time zero $\left[\mathrm{T}_{0}\right]$ in this study). The diagnostic delay interval was defined as the time between the subject's self-reported onset of an initial alpha-1 antitrypsin deficiency-attributable symptom and $\mathrm{T}_{0}$. To assure temporal coincidence of the subject's symptomatic and functional status at $\mathrm{T}_{0}$ with the subject's pulmonary function values, pulmonary function test results were deemed eligible if they were performed within a window of 6 months before to 6 months after $\mathrm{T}_{0}$ (Fig. 1A). Diagnostic delay interval was assigned the value of zero when the newly diagnosed subject was asymptomatic (eg, the family member of an individual affected with alpha-1 antitrypsin deficiency). The SGRQ was administered in a manner consistent with its being validated for telephonic use. ${ }^{19}$ Reference values for pulmonary function tests were based on the individual laboratory's standards but were usually based on the National Health and Nutrition Examination Survey ${ }^{20}$ or Knudson ${ }^{21}$ reference equations.

\section{Analytic Strategy and Statistical Methods}

The primary aim was to assess whether a delay in diagnosing alpha-1 antitrypsin deficiency is associated with worsened clinical status at the time of initial diagnosis. Scatterplots were prepared to graphically illustrate the association between the diagnostic delay and each clinical status outcome ( $\mathrm{FEV}_{1} \%$ predicted, SGRQ, and CAT). We overlaid both a least-squares (linear regression) line and a 
locally weighted smoothing curve. From each simple linear regression, the regression coefficient (slope) was tested to determine whether it significantly differed from zero, which indicated a linear association. Presented are the resulting slopes, $95 \% \mathrm{CIs}$, and $P$ values. Such analyses were repeated to assess the association among a number of health-care providers seen before initial diagnosis of alpha-1 antitrypsin deficiency and clinical status at $\mathrm{T}_{0}$. A subgroup analysis was performed for subjects with PI*ZZ.

A "decision tree" diagram was prepared to investigate which data features (diagnostic method, type of presenting alpha- 1 antitrypsin deficiency attributable symptom, smoking status, environmental exposures, and lung disease comorbidities) determined the diagnostic delay interval. In this procedure, all the data features are considered and different split points are tried and tested to find splits that generate groups of subjects with similar diagnostic delay intervals. In addition, a random forest was built to assess and rank the importance of each feature.

Sample-size calculations were conducted by using a linear regression test of the slope. When assuming an SD of $2 \mathrm{y}$ in the diagnostic interval and $20 \%$ in the $\mathrm{FEV}_{1} \%$ predicted, 60 participants would provide $80 \%$ power at a $5 \%$ significance level to detect a slope of at least $3 \%$ $\left(\mathrm{FEV}_{1} \%\right.$ predicted per year of diagnostic delay), thereby rejecting the null hypothesis that the slope is zero. All tests were 2-tailed and used a significance level of 0.05. Data were analyzed by using JMP Pro version 13 (SAS Institute, Cary, North Carolina) and SAS version 9.4 statistical software (SAS Institute).

\section{Results}

Forty subjects (31 with $\mathrm{PI}$ *ZZ, 9 with $\mathrm{PI} * \mathrm{SZ}$ ) participated in the study (Table 1). Twenty-two subjects (55\%) were female. The mean $\pm \mathrm{SD}$ age was $59.4 \pm 14.0$ y. Four subjects (10\%) were current smokers, and $21(58 \%)$ were ex-smokers. Reasons given for undergoing alpha-1 antitrypsin deficiency testing were the following: having a symptom ( $n=23[58 \%])$, having a symptom and a family member with alpha-1 antitrypsin deficiency $(n=6[15 \%])$, having a family member with alpha-1 antitrypsin deficiency but no personal symptoms $(n=5[12 \%])$, and having another reason to be tested $(n=6[15 \%])$. Therefore, 29 of the 40 (71\%) were diagnosed due to a symptom, usually dyspnea (Table 1). Eligible spirometry measurements were available for 17 subjects, SGRQ for all 40 subjects, and CAT for 32 subjects.

The median $\left(\mathrm{Q}_{1}-\mathrm{Q}_{3}\right.$; maximum) diagnostic delay interval for the entire cohort was 2.9 y $(0-10.7 \mathrm{y} ; 26.8 \mathrm{y})$ (Fig. 1B). For those 29 subjects diagnosed because of symptoms, the median $\left(\mathrm{Q}_{1}-\mathrm{Q}_{3}\right.$; maximum) diagnostic delay interval was longer, 5.0 y (2.3-15.9 y; 26.8 y) (Fig. 1C). For
Table 1. Demographic and Presenting Features of Study Subjects (at time 0)

\begin{tabular}{|c|c|}
\hline Feature & Result \\
\hline Age, mean \pm SD y & $59.4 \pm 14.0$ \\
\hline Female, $n(\%)$ & $22(55)$ \\
\hline Current smoker, $n(\%)$ & $4(10)$ \\
\hline Past smoker, $n(\%)$ & $21(58)$ \\
\hline \multicolumn{2}{|l|}{ Alpha-1 antitrypsin deficiency genotype, $n(\%)$} \\
\hline $\mathrm{PI} * \mathrm{ZZ}$ & $31(78)$ \\
\hline $\mathrm{PI}{ }^{*} \mathrm{SZ}$ & $9(22)$ \\
\hline Environmental exposure, $n(\%)^{*}$ & $6(16)$ \\
\hline \multicolumn{2}{|l|}{$\begin{array}{l}\text { Reason for undergoing alpha-1 antitrypsin } \\
\text { deficiency testing, } n(\%)\end{array}$} \\
\hline Symptoms present $\dagger$ & $23(58)$ \\
\hline $\begin{array}{l}\text { Symptoms present and a family member } \\
\text { was diagnosed with alpha-1 antitrypsin } \\
\text { deficiency } \dagger\end{array}$ & $6(15)$ \\
\hline $\begin{array}{l}\text { No symptoms present but a family } \\
\text { member was diagnosed with alpha-1 } \\
\text { antitrypsin deficiency }\end{array}$ & $5(12)$ \\
\hline $\begin{array}{l}\text { Other reason for seeking alpha-1 antitrypsin } \\
\text { deficiency testing } \neq\end{array}$ & $6(15)$ \\
\hline \multicolumn{2}{|c|}{ 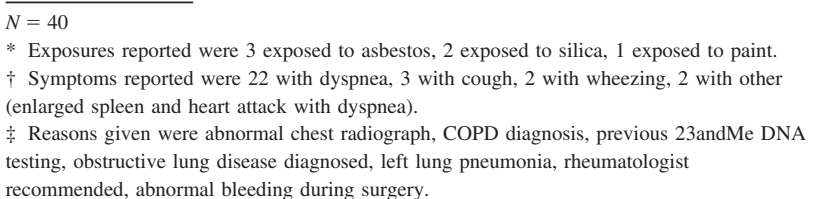 } \\
\hline
\end{tabular}

the 23 subjects with symptoms but no reported family member with alpha-1 antitrypsin deficiency, the median $\left(\mathrm{Q}_{1}-\mathrm{Q}_{3} ;\right.$ maximum) diagnostic delay interval was also $5.0 \mathrm{y}$ (2.9-14.9 y; 23.9 y).

An observational decision tree that indicated which features were most able to discriminate subjects who experienced a short versus long diagnostic delay interval is shown in Figure 2. The initial self-reported symptom, reason for alpha-1 antitrypsin testing, and smoking status were identified as most impactful. A missing value for a presenting symptom indicates that the subject had either no symptoms but a family member was diagnosed with alpha1 antitrypsin deficiency or that testing was performed for other reasons. Patients who presented with wheezing or other symptoms, or who underwent testing for a reason other than having a symptom or an affected family member also experienced short diagnostic delay intervals (mean $1.1 \mathrm{y})$. However, when patients presented with shortness of breath or cough and, in particular, were former smokers, the diagnostic delay interval was especially long (mean $12.5 \mathrm{y})$.

The median $\left(\mathrm{Q}_{1}-\mathrm{Q}_{3}\right.$; maximum) number of health-care providers seen before the initial diagnosis for the entire cohort was $2(1-3 ; 12)$. For the 29 patients who were ascertained because of alpha- 1 antitrypsin deficiency at- 


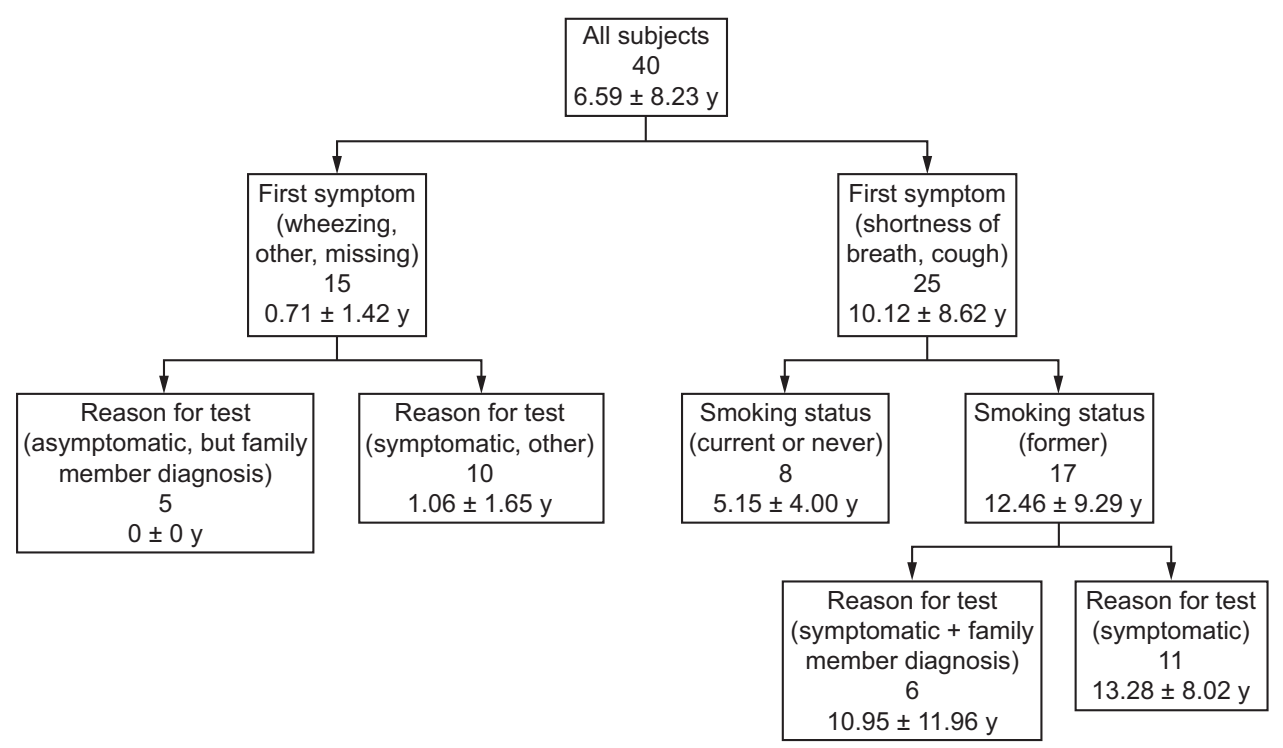

Fig. 2. Decision tree that indicates that the first symptom, reason for test, and smoking status were the variables most highly associated with diagnostic delay for alpha-1 antitrypsin deficiency. Mean \pm SD diagnostic delay intervals are shown.
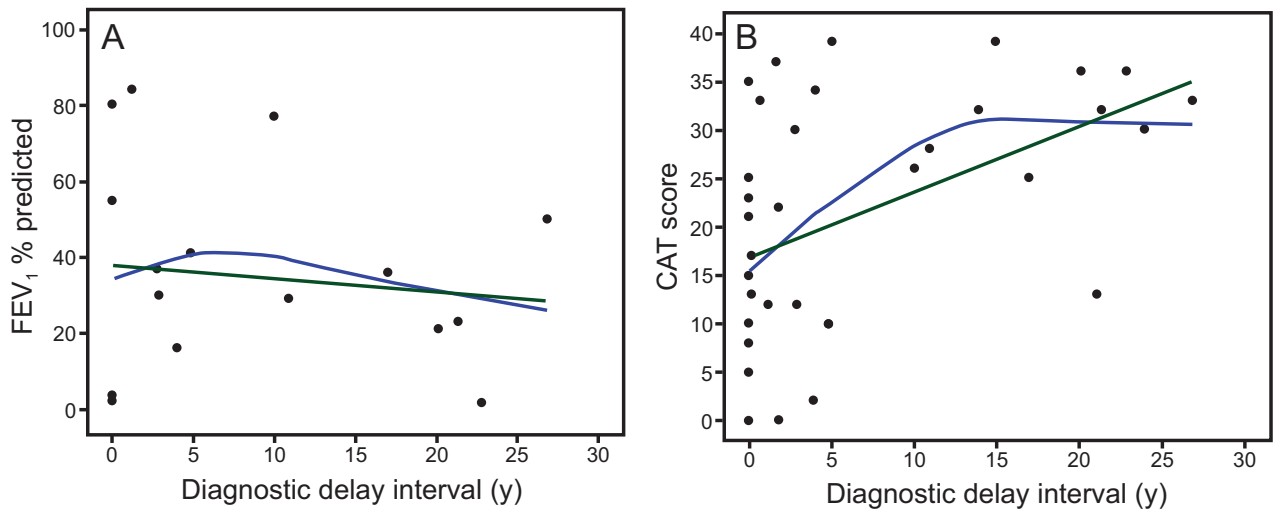

Fig. 3. Association between diagnostic delay interval with $\mathrm{FEV}_{1} \%$ predicted (A) or COPD Assessment Test (CAT) score (B). Dark green line represents a linear regression line. Blue line represents a locally weighted smoothing curve.

tributable symptoms, a median of 3 providers $(2-4 ; 12)$ were seen before alpha-1 antitrypsin deficiency was diagnosed, and 25 of the 29 subjects (86\%) saw multiple providers before initial diagnosis.

The relationship between diagnostic delay interval and clinical status was directionally consistent with an adverse impact of increasing diagnostic delay. The SGRQ Total score increased significantly (by 1.6 points $[P<.001]$ ) with increasing diagnostic delay, as did the CAT score (increased by 0.7 points $[P=.004]$ ) (Fig. $3 \mathrm{~A}$ and $\mathrm{B}$, Fig. 4A, Table 2) and all SGRQ component scores (all $P \leq .02$ ) (Table 2). For each additional year of diagnostic delay, the $\mathrm{FEV}_{1} \%$ predicted decreased by $0.3 \%$; this trend did not achieve statistical significance $(P=.66)$.

A significant relationship between an increasing numbers of providers seen and worsened clinical status was seen for SGRQ Total (Fig. 4B) and SGRQ Impact, with nonsignificant trends that were directionally consistent with an adverse impact of delayed diagnosis seen for SGRQ Symptoms, SGRQ Activity, and CAT. For example, for each additional provider seen before the initial diagnosis, the CAT score increased by 1.2 points $(P=.21)$. Similar analyses among only the 31 subjects with PI*ZZ showed directionally consistent results, with an adverse impact of increasing diagnostic delay and the number of health-care providers seen before the initial diagnosis (Table 2). This subgroup analysis eliminated the possibility that the results were confounded by milder disease in subjects with PI*SZ, some of whom may not have had clinical disease. When restricting the analysis to subjects with $\mathrm{PI}{ }^{*} \mathrm{ZZ}$, the relationship between $\mathrm{FEV}_{1} \%$ predicted and the number of health-care providers became consistent, with a detrimental effect (slope, -1.1 ), although the relationship remains nonsignificant $(P=.65)$. 

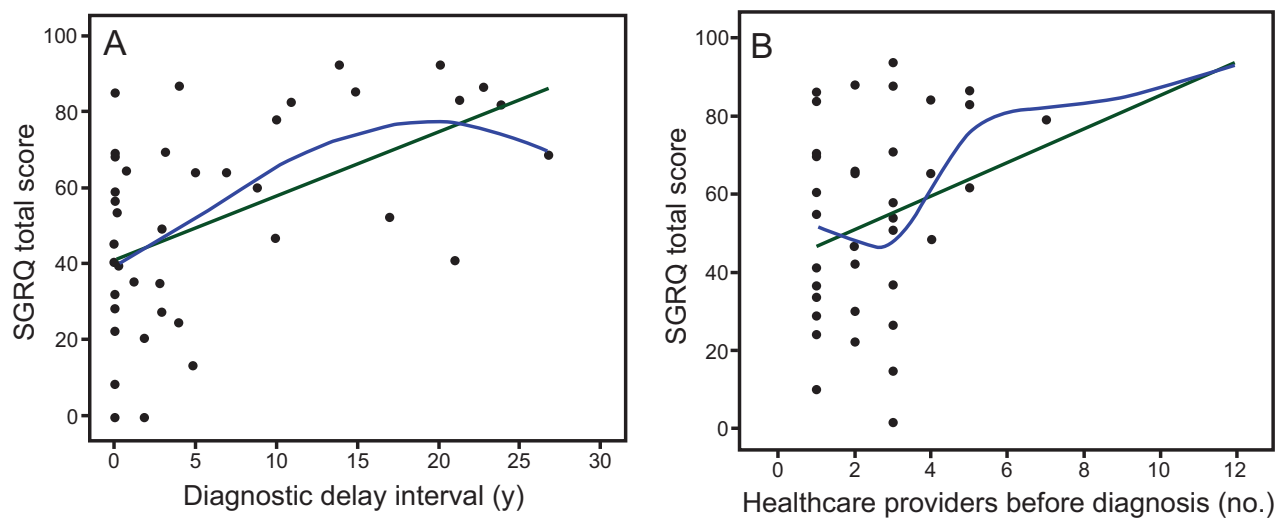

Fig. 4. Association between alpha-1 antitrypsin deficiency diagnostic delay interval $(A)$ or the number of health-care providers (B) and St George Respiratory Questionnaire (SGRQ) total score. Dark green line represents a linear regression line. Blue line represents a locally weighted smoothing curve.

Table 2. Associations Between Clinical Status at Time of Diagnosis and Diagnostic Delay and Number of Providers

\begin{tabular}{|c|c|c|c|c|c|}
\hline \multirow[t]{2}{*}{ Variable } & \multirow[t]{2}{*}{ No. Subjects } & \multicolumn{2}{|c|}{$\begin{array}{l}\text { Diagnostic Delay } \\
\text { (slope reported } \\
\text { per one year) }\end{array}$} & \multicolumn{2}{|c|}{$\begin{array}{l}\text { No. Health-Care Providers } \\
\text { Seen Before } \\
\text { Initial Diagnosis }\end{array}$} \\
\hline & & Slope $(95 \%$ CI) & $P$ & Slope $(95 \% \mathrm{CI})$ & $P$ \\
\hline \multicolumn{6}{|l|}{ All subjects } \\
\hline $\mathrm{FEV}_{1} \%$ predicted & 17 & $-0.3(-1.9$ to 1.2$)$ & .66 & $1.1(-4.1$ to 6.3$)$ & .66 \\
\hline \multicolumn{6}{|l|}{ SGRQ score } \\
\hline Total & 40 & $1.6(0.7-2.5)$ & $<.001$ & $4.3(0.4-8.1)$ & .03 \\
\hline Symptoms & 40 & $2.0(1.1-2.8)$ & $<.001$ & $3.9(-0.1$ to 8.0$)$ & .06 \\
\hline Activity & 40 & $1.3(0.2-2.4)$ & .02 & $3.5(-1.0$ to 8.0$)$ & .12 \\
\hline Impact & 40 & $1.7(0.8-2.6)$ & $<.001$ & $4.8(0.9$ to 8.7$)$ & .02 \\
\hline CAT & 32 & $0.7(0.2-1.1)$ & .004 & $1.2(-0.7$ to 3.2$)$ & .21 \\
\hline \multicolumn{6}{|l|}{ PI*ZZ subjects only } \\
\hline $\mathrm{FEV}_{1} \%$ predicted & 13 & -0.3 ( -1.8 to 1.2$)$ & ND & $-1.1(-6.1$ to 4.0$)$ & ND \\
\hline \multicolumn{6}{|l|}{ SGRQ score } \\
\hline Total & 31 & $1.7(0.7-2.6)$ & ND & $4.4(-0.1$ to 8.9$)$ & $\mathrm{ND}$ \\
\hline Symptoms & 31 & $1.9(1.0-2.8)$ & ND & $3.2(-1.4$ to 7.9$)$ & ND \\
\hline Activity & 31 & $1.5(0.2-2.7)$ & ND & $3.8(-1.6$ to 9.3$)$ & ND \\
\hline Impact & 31 & $1.7(0.8-2.7)$ & ND & $5.1(0.8$ to 9.5$)$ & ND \\
\hline CAT & 25 & $0.7(0.3-1.1)$ & ND & $1.5(-0.6$ to 3.7$)$ & ND \\
\hline \multicolumn{6}{|c|}{$\begin{array}{l}\text { SGRQ }=\text { St George Respiratory Questionnaire } \\
\text { CAT }=\text { COPD Assessment Test } \\
\text { ND }=\text { no data }\end{array}$} \\
\hline
\end{tabular}

\section{Discussion}

The results of this study showed that a longer diagnostic delay was associated with worsened clinical status (as characterized by SGRQ and CAT) at the time of the initial diagnosis. The association between diagnostic delay and lower $\mathrm{FEV}_{1} \%$ predicted at $\mathrm{T}_{0}$, although not achieving statistical significance, was also directionally consistent with an adverse effect of delayed diagnosis. Similarly, as the number of health-care providers seen for alpha-1 antitrypsin deficiency attributable symptoms increased, the pa- tient's clinical status worsened based on SGRQ Total, Impacts, and Symptom scores.

The current study extended available knowledge by showing that diagnostic delay was associated with clinical worsening in alpha- 1 antitrypsin deficiency, which thereby reinforces the imperative to establish a diagnosis, as has

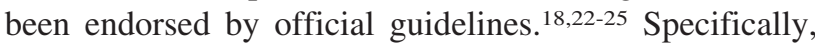
the 2003 American Thoracic Society/European Respiratory Society guideline ${ }^{18}$ recommends testing all adults with symptoms by using fixed air-flow obstruction on pulmonary function tests for alpha- 1 antitrypsin deficiency, 


\section{Diagnostic Delay in Alpha-1 Antitrypsin Deficiency}

ideally with both a serum alpha-1 antitrypsin level and a genotype. ${ }^{22}$ Canadian, ${ }^{23}$ Argentinian, ${ }^{24}$ and Spanish ${ }^{25}$ guidelines also recommend testing for alpha-1 antitrypsin deficiency in individuals with fixed air-flow obstruction. Clear evidence showed that alpha-1 antitrypsin deficiency was associated, on average, with an accelerated decline in lung function, with an estimated average yearly $\mathrm{FEV}_{1}$ decline of 67, 54, and $109 \mathrm{~mL} / \mathrm{y}$ for never, ex-, and current smokers, respectively, in the National Heart, Lung, and Blood Institute Registry for Individuals with Severe Deficiency of Alpha-1 Antitrypsin. ${ }^{8,18}$ This and other findings suggest that a delayed diagnosis poses risk for harm, but, to our knowledge, this point had not been previously definitively demonstrated.

In this way, the current study extends previous knowledge. Indirect previous evidence of harm associated with a delayed diagnosis of alpha-1 antitrypsin deficiency was suggested in an early study by Stoller et al. ${ }^{1}$ In a cohort of 300 individuals with $\mathrm{PI}{ }^{*} \mathrm{ZZ}$, the frequency of self-reported adverse sequelae of alpha- 1 antitrypsin deficiency on relationships, employment, and insurance status was high, with $75.3 \%$ of respondents reporting at least one such adverse effect. Also, Tanash et al ${ }^{14}$ showed that individuals symptomatic for alpha- 1 antitrypsin deficiency and with lung symptoms had shortened survival compared with normal age- and sex-matched groups, whereas individuals who were asymptomatic and with alpha- 1 antitrypsin deficiency and who were diagnosed because a family member was diagnosed with alpha- 1 antitrypsin deficiency had a normal prognosis.

The current study tightens the association between the duration of a diagnostic delay (and the number of health-care providers seen before an initial diagnosis) and worsened clinical status at the time of the initial diagnosis by demonstrating significant associations between the duration of the delay and the magnitude of the clinical effect on validated measures of functional and symptomatic status. For example, with a minimally important clinical difference of 4 points for the SGRQ ${ }^{26}$ and of 2 points for the CAT score, ${ }^{27}$ analysis of the current data indicated that a diagnostic delay of 2.5-3 y was associated with a clinically important deterioration of functional and symptomatic status (as SGRQ rose by 1.6 points and CAT rose by 0.7 points per year of diagnostic delay [Table 2]).

Limitations of this study warrant discussion. First, because the date of the onset of the first attributable alpha1 antitrypsin deficiency symptom was subjected to the patient's recall, the diagnostic delay interval was necessarily self-reported and not subjected to independent confirmation. Although this limitation affects many studies that reported the diagnostic delay interval, $1,2,4,6,7$ the striking consistency of median estimates between 5 and $8 \mathrm{y}$ across many studies over time supports the robustness of the estimates. Notably, the overall median value of $2.9 \mathrm{y}$ of diagnostic delay in the current study was likely diminished by inclusion of subjects who were asymptomatic in this series and who were diagnosed because of a family history of alpha-1 antitrypsin deficiency. Specifically, for the 23 subjects with symptoms but without a family member with an alpha-1 antitrypsin deficiency that might have prompted earlier testing in the current study, the median $\left(\mathrm{Q}_{1}-\mathrm{Q}_{3}\right)$ diagnostic delay interval (5.0 [2.9-14.9] y) closely resembles previous estimates.

The current study was underpowered to show an impact of the diagnostic delay on $\mathrm{FEV}_{1} \%$ predicted. Initial power calculations indicated that 60 subjects were needed to show a $3 \%$ per year decline in $\mathrm{FEV}_{1} \%$ predicted by year of diagnostic delay, but study accrual was slower than projected. Furthermore, spirometry measurements within the predefined time eligibility window were available for only 17 of the 40 subjects, which potentially confounded the observed relationship between the $\mathrm{FEV}_{1} \%$ predicted and diagnostic delay interval. That said, with recognizing the small number of subjects involved, those 17 subjects with eligible spirometry measurements available were representative of the entire cohort regarding demographic and presentation features (see Supplementary Table 1 at http:// www.rcjournal.com). Also, the association between a longer diagnostic delay and lower $\mathrm{FEV}_{1} \%$ predicted was directionally consistent with an adverse effect of a diagnostic delay.

\section{Conclusions}

In showing a significant association between a longer diagnostic delay and worsened clinical status at the time of initial presentation in alpha-1 antitrypsin deficiency, the current study underscored the importance of early diagnosis of alpha-1 antitrypsin deficiency, in keeping with multiple official guideline recommendations. ${ }^{8,18,22,25}$ An early diagnosis permits aggressive smoking cessation efforts, guidance on avoidance of inhaled particulates that have been associated with worsened clinical status in alpha1 antitrypsin deficiency, ${ }^{28}$ and targeted detection of firstdegree relatives of the proband in this autosomal codominant condition. The current availability of augmentation therapy, which has been shown to slow emphysema progression in alpha- 1 antitrypsin deficiency ${ }^{9}$ and the prospect of new and emerging therapies ${ }^{29}$ reinforce this recommendation.

\section{REFERENCES}

1. Stoller JK, Smith P, Yang P, Spray J. Physical and social impact of alpha-1 antitrypsin deficiency: Results of a mail survey of the readership of a national newsletter. Cleve Clin J Med 1994;61(6):461467. 


\section{Diagnostic Delay in Alpha-1 Antitrypsin Deficiency}

2. Stoller JK, Brantly M. The challenge of detecting alpha-1 antitrypsin deficiency. COPD 2013;10(Suppl 1):26-34.

3. Stoller JK, Aboussouan LS. A review of $\alpha 1$-antitrypsin deficiency. Am J Respir Crit Care Med 2012;185(3):246-259.

4. Campos MA, Wanner A, Zhang G, Sandhaus RA. Trends in the diagnosis of symptomatic patients with alpha- 1 antitrypsin deficiency between 1968 and 2003. Chest 2005;128(3):1179-1186.

5. Köhnlein T, Janciauskiene S, Welte T. Diagnostic delay and clinical modifiers in alpha- 1 antitrypsin deficiency. Ther Adv Respir Dis 2010;4(5):279-287.

6. Greulich T, Ottaviani S, Bals R, Lepper PM, Vogelmeier C, Luisetti M, Ferrarotti I. Alpha-1 antitrypsin deficiency - diagnostic testing and disease awareness in Germany and Italy. Respir Med 2013; 107(9):1400-1408.

7. Stoller JK, Sandhaus RA, Turino G, Dickson R, Rodgers K, Strange C. Delay in diagnosis of alpha-1 antitrypsin deficiency: A continuing problem. Chest 2005;128(4):1989-1994.

8. The Alpha-1 antitrypsin Deficiency Registry Study Group, prepared by Crystal RG, Buist AS, Fallat RJ, Gadek JE, Schluchter MD, Stoller JK, Turino GM, Vreim CE, Wu MC, Zhang R. Survival and rate of FEV1 decline in subjects enrolled in the NHLBI Registry of Patients with Severe Deficiency of Alpha-1 antitrypsin. Am J Respir Crit Care Med 1998;158(1):49-59.

9. Chapman KR, Burdon JG, Piitulainen E, Sandhaus RA, Seersholm N, Stocks JM, et al.; RAPID Trial Study Group. Intravenous augmentation treatment and lung density in severe alpha- 1 antitrypsin deficiency (RAPID): a randomized, double-blind, placebo-controlled trial. Lancet 2015;386(9991):360-368.

10. Schoepfer AM, Dehlavi MA, Fournier N, Safroneeva E, Straumann A, Pittet V, et al.; IBD Cohort Study Group. Diagnostic delay in Crohn's disease is associated with a complicated disease course and increased operation rate. Am J Gastroenterol 2013;108(11):17441753; quiz 1754

11. Lipka S, Kumar A, Richter JE. Impact of diagnostic delay and other risk factors on eosinophilic esophagitis phenotype and esophageal diameter. J Clin Gastroenterol 2016;50(2):134-140.

12. Haroon M, Gallagher P, FitzGerald O. Diagnostic delay of more than 6 months contributes to poor radiographic and functional outcome in psoriatic arthritis. Ann Rheum Dis 2015;74(6):1045-1050.

13. Seo MR, Baek HL, Yoon HH, Ryu HJ, Choi HJ, Baek HJ, Ko KP. Delayed diagnosis is linked to worse outcomes and unfavourable treatment responses in patients with axial spondyloarthritis. Clin Rheumatol 2015;34(8):1397-1405.

14. Tanash HA, Nilsson PM, Nilsson JA, Piitulainen E. Clinical course and prognosis of never-smokers with severe alpha-1 antitrypsin deficiency (PiZZ). Thorax 2008;63(12):1091-1095.

15. Jones PW, Quirk FH, Baveystock CM, Littlejohns P. A self-complete measure of health status for chronic airflow limitation. The St. George's Respiratory Questionnaire. Am Rev Respir Dis 1992;145(6): 1321-1327.

16. Jones PW, Harding G, Berry P, Wiklund I, Chen WH, Kline Leidy N. Development and first validation of the COPD Assessment Test. Eur Respir J 2009;34(3):648-654.
17. Jones PW. COPD assessment test - rationale, development, validation and performance. COPD 2013;10(2):269-271

18. American Thoracic Society, European Respiratory Society. American Thoracic Society/European Respiratory Society statement: Standards for the diagnosis and management of individuals with alpha-1 antitrypsin deficiency. Am J Respir Crit Care Med 2003;168(7):818900

19. Anie KA, Jones PW, Hilton SR, Anderson HR. A computerassisted telephone interview technique for assessment of asthma morbidity and drug use in adult asthma. J Clin Epidemiol 1996; 49(6):653-656.

20. Hankinson JL, Odencrantz JR, Fedan KB. Spirometric reference values from a sample of the general U.S. population. Am J Respir Crit Care Med 1999;159(1):179-187.

21. Knudson RJ, Lebowitz MD, Holberg CJ, Burrows B. Changes in the normal maximal expiratory flow-volume curve with growth and aging. Am Rev Respir Dis 1983;127(6):725-734.

22. Sandhaus RA, Turino G, Brantly ML, Campos M, Cross CE, Goodman $\mathrm{K}$, et al. The diagnosis and management of alpha-1 antitrypsin deficiency in the adult. Chronic Obstr Pulm Dis 2016; 3(3):668-682.

23. Marciniuk DD, Hernandez P, Balter M, Bourbeau J, Chapman KR, Ford GT, et al; Canadian Thoracic Society COPD Clinical Assembly Alpha-1 Antitrypsin Deficiency Expert Working Group. Alpha-1 antitrypsin deficiency targeted testing and augmentation therapy: a Canadian Thoracic Society clinical practice guideline. Can Respir J 2012;19(2):109-116

24. Menga G, Miravitlles M, Blanco I, Echazarreta AL, Rossi SE, Sorroche $\mathrm{PB}$, et al. Normativas de diagnóstico y tratamiento del déficit de alfa-1 antitripsina Asociación Argentina de Medicina Respiratoria [Guidelines on Diagnosis and Treatment of Alpha-1 Antitrypsin Deficiency]. RAMR 2014;1:28-46. Available at http://www.ramr.org/ articulos/volumen_14_numero_1/articulos_especiales/articulo_especial_ normativas_diagnostico_tratamiento_alfa1.php

25. Vidal R, Blanco I, Casas F, Jardí R, Miravitlles M; Committee on the National Registry of Individuals with Alpha-1 Antitrypsin Deficiency. [Guidelines for the diagnosis and management of alpha-1 antitrypsin deficiency]. Arch Bronconeumol 2006;42(12): 645-659.

26. Jones PW. St. George's Respiratory Questionnaire: MCID. COPD 2005;2(1):75-79.

27. Kon SS, Canavan JL, Jones SE, Nolan CM, Clark AL, Dickson MJ, et al. Minimum clinically important difference for the COPD Assessment Test: a prospective analysis. Lancet Respir Med 2014;2(3): 195-203.

28. Mayer AS, Stoller JK, Bartelson Bartelson B, James Ruttenber A, Sandhaus RA, Newman LS. Occupational exposure risks in individuals with PI*Z alpha-1 antitrypsin deficiency. Am J Respir Crit Care Med 2000;162(2 Pt 1):553-558.

29. Hatipoğlu U, Stoller JK. Alpha-1 antitrypsin deficiency. Clin Chest Med 2016;37(3):487-504. 